\title{
CONSIDERAÇÕES SOBRE ELEMENTOS TEÓRICOS E METODOLÓGICOS DA RELAÇÃO ENTRE SOCIEDADE, DIREITO E TECNOLOGIA
}

\author{
CONSIDERATIONS ON THEORETICAL AND METHODOLOGICAL ELEMENTS OF THE \\ RELATIONSHIP BETWEEN SOCIETY, LAW AND TECHNOLOGY
}

Vick Mature Aglantzakis

Mestrando em Prestação Jurisdicional e Direitos Humanos na Universidade Federal do Tocantins - UFT; Especialista em Direito Civil e Processo Civil pela Universidade Estácio de Sá - UNESA; Graduado em Bacharelado em Direito pela Universidade Federal de Roraima - UFRR.

E-mail: vickmature@gmail.com

\section{David Nadler Prata}

Doutor em Ciência da Computação pela Universidade Federal de Campina Grande - UFCG; Mestre em Ciência da Computação pela Universidade Federal da Paraíba - UFPB; Professor Associado da Universidade Federal do Tocantins - UFT - Integrante do corpo docente do Programa de Pós-Graduação Stricto Senso - Prestação Jurisdicional e Direitos Humanos (PPGPJDH) - Mestrado Profissional da Universidade Federal do Tocantins - UFT e Coordenador do Pós-Gradução Stricto Sensu em Modelagem Computacional de Sistema (PPGMCS) - Mestrado e Doutorado - da Universidade Federal do Tocantins - UFT.

E-mail: ddnprata@gmail.com

Recebido em: 29/06/2020

Aprovado em: 27/11/2020

RESUMO: O presente artigo tem como objetivo de forma reflexiva, apresentar elementos teóricos e metodológicos essenciais à compreensão da relação existente entre sociedade, direito e tecnologia, os quais possibilitarão o estabelecimento de considerações sobre o lugar do direito na Sociedade da Informação. No plano metodológico foi utilizado o raciocínio lógico-dedutivo, bem como, o raciocínio analítico reflexivo. A abordagem foi de natureza qualitativa e interdisciplinar, possibilitando a análise dos objetos em estudo e das variadas dimensões que envolvem a relação a ser estudada. $\mathrm{O}$ artigo foi desenvolvido em cinco seções. Na primeira foi apresentada a introdução; na segunda foram abordados aspectos teóricos e relacionais entre sociedade, direito e tecnologia; na terceira sessão foram apresentados os pressupostos metodológicos da relação entre sociedade, direito e tecnologia, a partir de uma perspectiva histórico-reflexiva; na quarta seção foram feitas considerações pontuais sobre a inserção do direito na Sociedade da Informação e; na quinta seção foram apresentadas as considerações finais com reflexões pontuais sobre o tema desenvolvido, especialmente no tocante ao acesso à justiça e a prestação jurisdicional por meio do processo judicial eletrônico.

Palavras-chave: Direito e Tecnologia. Sociedade da Informação. Acesso à Justiça e Prestação Jurisdicional. Processo Judicial Eletrônico. 


\begin{abstract}
This article aims in a reflexive way to present theoretical and methodological elements essential to the understanding of the relationship between society, law and technology, which will enable the establishment of considerations about the place of law in the Information Society. In the methodological plane, logical-deductive reasoning was used, as well as reflexive analytical reasoning. The approach was qualitative and interdisciplinary, enabling the analysis of the objects under study and the various dimensions that involve the relationship to be studied. The article was developed in five sections. In the first one was presented the introduction; in the second, theoretical and relational aspects between society, law and technology were addressed; in the third session, the methodological assumptions of the relationship between society, law and technology were presented from a historical-reflexive perspective; in the fourth section, specific considerations were made about the insertion of law in the Information Society and; in the fifth section, the final considerations were presented with specific reflections on the developed theme, especially regarding access to justice and judicial provision through the electronic judicial process.
\end{abstract}

Keywords: Law and Technology. The Information Society. Access to Justice and Judicial Provision. Electronic Lawsuit.

SUMÁRIO: Introdução; 1. Aspectos teóricos e relacionais entre sociedade, direito e tecnologia; 2. Pressupostos metodológicos para o estudo da relação entre sociedade, direito e tecnologia; 3 . O direito e sua inserção na sociedade da informação; Considerações finais; Referências

\title{
INTRODUÇÃO
}

As novas possibilidades tecnológicas e a sua inserção no cotidiano social estabeleceram novos parâmetros científicos para a análise da relação existente entre sociedade, direito e tecnologia. Esses, em razão de suas complexidades existenciais, ora se situam como objeto, ora como lugares de saber e produção do conhecimento científico, tornando necessário um deslocamento do pesquisador do seu lugar de fala e produção do saber, para transcender ao conhecimento já estabelecido.

A mudança de perspectiva, no entanto, não é algo fácil. Ela necessita de uma abertura ao que se apresenta como novo, num processo dialogal compreensivo, por meio do qual se viabilize, não só a transformação dos mecanismos formais de conhecimento, mas, também, o reconhecimento de sua multiplicidade e validade em coexistência.

Nesse plano, o presente artigo tem como objetivo apresentar elementos teóricos e metodológicos essenciais à compreensão da relação existente entre sociedade, direito e tecnologia, os quais possibilitarão a reflexão sobre o lugar do direito na Sociedade da Informação.

Ao buscar a compreensão da relação entre os fenômenos sociais já especificados, metodologicamente optou-se pelo raciocínio lógico-dedutivo, sem perder de vista a possibilidade de utilização do raciocínio analítico reflexivo. A abordagem a ser desenvolvida terá natureza qualitativa e interdisciplinar, pois, por meio dessas, torna-se possível a análise dos objetos em estudo e das variadas dimensões que envolvem a relação a ser estudada.

Na sequência da presente apresentação, a segunda seção abordará, de maneira tópica, aspectos teóricos e relacionais entre sociedade, direito e tecnologia, com o fito de estabelecer as conexões quanto à sua origem e a importância do seu estudo.

$\mathrm{Na}$ terceira seção serão abordados os pressupostos metodológicos da relação entre sociedade, direito e tecnologia a partir de uma perspectiva histórico-reflexiva das mudanças ocorridas na forma de desenvolvimento das pesquisas científicas e do trânsito do conhecimento produzido de um paradigma a outro. 
A quarta seção apresentará considerações pontuais sobre a inserção do direito na Sociedade da Informação e a importância dessa nova realidade para a transformação das práticas jurídicas e para a própria definiç̧ão do direito.

Na quinta seção serão apresentadas considerações finais de natureza reflexiva à temática tratada, bem como, sobre elementos objetivos relacionados ao conteúdo desenvolvido, com o intuito de evidenciar a importância do estudo da relação entre sociedade, direito e tecnologia e a capacidade transformadora que esta tem nas diversas áreas do conhecimento.

\section{ASPECTOS TEÓRICOS E RELACIONAIS ENTRE SOCIEDADE, DIREITO E TECNOLOGIA}

O alvorecer do século XXI traz consigo dilemas existenciais e relacionais que envolvem uma miríade de conhecimentos e práticas sociais, culturais, políticas, econômicas e tecnológicas, produzidas e transformadas nas múltiplas revoluções empreendidas no transcorrer dos dois últimos séculos, em especial a partir do período que compreende as duas Grandes Guerras Mundiais e o período pós Segunda Guerra Mundial. Tais revoluções, longe de trazerem resoluções conclusivas aos problemas que se propunham a resolver, ampliaram as incertezas existentes, fazendo surgir novos desafios voltados às novas soluções.

Entre as diversas vertentes relacionais, essenciais à dinâmica da vida em sociedade, submetidas às revoluções empreendidas no século XX e em curso no século XXI, encontra-se a que envolve: a sociedade na sua dimensão ampla e relacional, conformadora do Estado, no qual se insere as micro concepções societárias de dimensões nucleares; o direito como instrumento normativo e procedimental de controle e normalização social; e a tecnologia, aqui posta como campo de saber, produtora de novas possibilidades teóricas e práticas de soluções aos desafios postos pelas novas e velhas formas relacionais da sociedade, bem como na condição de produtos decorrente das teorias voltadas à instrumentalização técnica.

Como elemento inicial a ser considerado, que é comum à sociedade, ao direito e à tecnologia, encontra-se a polissemia que envolve a definição de cada um. A natureza polissêmica dos conceitos desses fenômenos sociais determina, em razão dos objetivos aqui pretendidos, a fixação de alguns limites necessários à compreensão da relação existente, ora em análise.

A primeira delimitação a ser posta se circunscreve à sociedade, que será tomada como lugar de produção de conhecimento e práticas sociais que se consolidam por meio das interações dos indivíduos, as quais significam e ressignificam as suas relações num processo contínuo de choques e conflitos que lhe são inerentes.

O direito será tomado, a priori, como instrumento de controle social, normatizador e normalizador das relações sociais e dos processos de transformação que delas se originam, e, também, como campo de conhecimento que se projeta para além do círculo tecnocrático, possibilitando, não só a sua percepção, mas, também, a sua exteriorização, através da sua procedimentalização, numa perspectiva plural, tal qual a sociedade a que serve.

A tecnologia será tratada como espaço de produção de conhecimento, para analisar os produtos técnicos que são colocados à disposição da sociedade e sobre os quais o direito se estabelece, regulando os seus usos e trocas, de natureza material ou simbólica.

Ainda atinente à tecnologia, será destacada a sua circularidade no plano relacional com a sociedade e o direito, estando ora submetidos ao seu controle, ora submetendo-os às novas possibilidades de existência e práticas sociais, sob uma ótica que ultrapasse os limites da idealização e se projetem a um plano de efetiva viabilização, por meio dos instrumentos tecnológicos à disposição da sociedade, de um acesso à justiça e uma prestação jurisdicional ampla e fundada em preceitos de equidade.

Fixadas as delimitações dos fenômenos a serem pontualmente analisados, tratar-se-á primeiramente da sociedade, para na sequência, do direito e, por fim, da tecnologia. Na sequência, 
serão identificados alguns aspectos relacionais existentes e necessários à compreensão da importância da conexão que há entre estes fenômenos sociais.

A sociedade enquanto fenômeno social, ocorre a partir da conformação de indivíduos em processos relacionais, baseada em instituições nucleares fundamentais à formação de sistemas interacionais, tais como: um sistema de comunicação, um sistema ritualístico, um sistema econômico e, sobretudo, um sistema de poder e autoridade (BOTTOMORE, 1987, p. 122).

A partir dessa perspectiva conceitual primária de sociedade tem-se uma macroestrutura social que se diferencia e se especializa, individualizando os grupos sociais, dando-lhes identidade e especificidades, tornando-a um espaço de produção de saber e conhecimento, numa perspectiva plural, os quais se originam, são extintos, se transformam ou se adaptam ao tempo e espaço da sua existência.

No plano fenomênico social, considerando ainda a conformação conceitual de sociedade, agregando fatos sociais que diferenciam e especificam os grupos sociais, esta existe como unidade e pluralidade. Ela pode ser concebida como unidade, mas não deve perder o seu pertencimento antecedente de parte de uma universalidade, pois, partindo do conceito posto, a sociedade emerge da pluralidade que com ela coexiste em processos paralelos de agregação e desagregação.

Um passo antecedente à compreensão da sociedade na sua dimensão ampla e relacional, situa-se a compreensão do lugar do indivíduo como elemento essencial à sua conformação. $\mathrm{O}$ indivíduo, tomado aqui como homem, realiza a sua existência de forma relacional, em processo de interação constante com outros indivíduos, produzindo e consumindo cultura.

A partir de tal premissa, pode-se conceber que a sociedade "é um sistema de interrelações que envolve os indivíduos coletivamente" (GIDDENS, 2008, p.22). Assim, enquanto macrossistema, funda-se em sistemas interacionais que se interconectam, viabilizando as relações interindividuais, e o envolvimento dos indivíduos no plano coletivo se dá a partir da cultura, fundada no sistema comunicacional.

A cultura de uma sociedade compreende aspectos intangíveis e tangíveis. Aos primeiros correspondem as crenças, as ideias e os valores; aos segundos os objetos, os símbolos e a tecnologia. Logo, não há como se falar em cultura fora de um determinado conjunto social, pois um necessita do outro para sua existência, dando-lhe sentido e identidade, abrindo, com isso, espaço para as variações culturais e os diferentes tipos de sociedade (GIDDENS, 2008, p.22).

Cultura e sociedade são indissociáveis. Aquela reside nesta que a produz, a transforma, lhe dá significado e, dentro de processos complexos de transformação do conhecimento produzido e reproduzido, pode vir a extingui-la ou ressignificá-la, gerando os sistemas derivativos do sistema comunicacional.

O sistema ritualístico, conjuntamente com o sistema comunicacional, permeia todo sistema de poder e autoridade, bem como o sistema econômico. Todos os sistemas fundantes trazem consigo aspectos tangíveis e intangíveis, produzidos culturalmente pelo homem e transmitidos por uma cadeia ancestral através de diversos processos de educação.

A cultura por meio dos sistemas estruturantes da sociedade estabelece padrões comportamentais e ideias dominantes aos sujeitos a ela pertencentes. Os indivíduos que a integram assimilam por meio do sistema de comunicação e de outras interações simbólicas "seus costumes, hábitos, crenças e valores, os pontos de vista que os congregam como entidade social" (CARMO, 2007, p.101), conformando todo um modo de existir no meio social.

A simbiose existente entre sociedade e cultura faz com que uma não exista sem a outra. A cultura habita a sociedade, e esta produz e reproduz aquela por meio dos múltiplos fenômenos inter-relacionais que lhe configuram como unidade identitária. Dito isso, projeta-se claramente a configuração do meio social como o lugar no qual o conhecimento se produz e se transforma culturalmente através das práticas sociais que são significadas e ressignificadas por gerações.

Ao se considerar a cultura como sistema fundante dos sistemas interacionais que se interconectam, pode-se afirmar que ela gera fenômenos sociais que ao se constituírem como 
conhecimento específico dos sistemas interacionais, se tornam campo de produção de conhecimento e práticas sociais que dinamizam e regulam a vida social, como o direito e a tecnologia.

O direito se constitui como fenômeno social decorrente de fato cultural e atua em e por meio dos sistemas interacionais estruturantes da sociedade. Tal situação se visibiliza a partir da significação de valores, crenças, símbolos e práticas que se estabelecem como limites de coexistência entre os indivíduos nas suas relações interindividuais (REALE, 1998, p.191).

A cultura ao valorar as condutas estabelece dimensões distintas da sua existência: a dimensão do ser e a do dever ser. Esta existe no direito, aquela fora dele. A cultura, por meio do direito, ao estabelecer padrões sociais, valora as ações humanas e estabelece direitos e deveres aos indivíduos com o objetivo de equilibrar as tensões sociais existentes, e tem como razão os interesses interindividuais divergentes que geram situações conflitivas.

O dever ser do direito, ao se estabelecer normativamente de maneira impositiva ao conjunto social, realiza um ideal de convivência voltado à satisfação do respeito à pessoa humana, constituindo-se, portanto, em princípio de ordem, com a finalidade de atender e expressar uma exigência ética e moral. Daí que, "o valor de um sistema de direito é dado pelos valores éticos que realiza na sociedade regulada, isto é, como fator de seu aperfeiçoamento e de seu progresso" (REALE, 1998, p. 210).

A partir da perspectiva culturalista de Miguel Reale, aqui considerada como um referencial teórico essencial à compreensão da relação entre cultura jurídica e temporalidade, o direito é fato, valor e norma, devendo ser compreendido a partir dessas três dimensões, pois, se assim não for, cometer-se-á equívoco de análise e de percepção da realidade imanente à natureza do direito e da sua relação com a realidade histórico-cultural que a determina (REALE, 1999, p. 699).

De tal modo, o valor culturalmente atribuído a um determinado fato social, ao ser apreendido pelo direito, se torna fato jurídico, que se transforma em norma jurídica. Essa, por sua vez, se materializa socialmente como instrumento de regulação social, necessária à sociedade, que se personifica no Estado, e passa a reger as condutas sociais tanto no âmbito privado, quanto no público.

Logo, onde há sociedade, há indivíduos em processo de interação de condutas intersubjetivas, e delas surgem conflitos de interesse. Em razão desses se origina o direito, o qual se constitui como manifestação de poder do Estado e tem natureza impositiva, determinando comportamentos padrões de normalidade social, segundo os valores culturalmente estabelecidos por uma determinada sociedade. Não há direito sem conflito e este não existe sem impositividade.

Ao tratar da relação entre o direito e o poder que lhe origina, bem como sua função de normalização social, J. J. Calmon de Passos afirma que:

$\mathrm{O}$ direito, consequentemente, antes de ser um agente conformador ou transformador da convivência social, é, quase que exclusivamente, um instrumento assegurador de determinado modelo de convivência, o que só alcança em virtude de sua impositividade que, por sua vez, o vincula, necessariamente ao poder político institucionalizado. Sem poder não há impositividade e sem impositividade não há direito. (PASSOS, 2000, p.51).

A cogência da norma jurídica, produzida pelo direito, impõe ao meio social padrões de normalidade que se espraiam por todas as relações sociais, inclusive, nos modos de produção do conhecimento. Com isso, estabelece um atuar do direito para além do controle da conduta realizada, manifestando-se no modo de produção da verdade a ser considerada no âmbito das relações sociais, da sua normatização e normalização social.

Aqui, cabe uma breve digressão à noção do direito como campo de conhecimento, por meio do qual o direito, como produto da cultura, se submente ao direito, enquanto conhecimento 
dado e campo de produção do saber científico, constituidor de verdades científicas postas, que deve ser observado como paradigma a ser seguido socialmente.

O direito, como campo de saber, por meio do qual são desenvolvidos os paradigmas científicos do conhecimento jurídico, acaba por regular não só as condutas relacionais comuns da sociedade, mas também, o próprio processo de produção cultural, que terá impacto no desenvolvimento tecnológico e na disseminação dos produtos advindos dele.

Como todo conhecimento científico, o direito se manifesta em lugares distintos, pois os paradigmas científicos por ele constituídos irão coexistir em posições distintas. Terão aqueles que se situarão como hegemônicos e outros que se encontrarão à margem, num processo que impacta na produção do conhecimento jurídico, assim como, nos qualificados como não jurídicos, tal qual os tecnológicos lato sensu.

Neste momento a compreensão do direito, enquanto produto de um campo específíco do conhecimento específico, deve ultrapassar as fronteiras do ideal e se materializar no cotidiano daqueles que não se encontram no lugar comum dos teóricos jurídicos, a fim de possibilitar uma assimilação natural e aberta das normas jurídicas e da sua procedimentalidade no cotidiano (HÄBERLE, 1997, p.24), ampliando, com isso, a participação da interpretação e materialização do direito na sociedade, bem como a sua atualização ao contexto tecnológico no qual está inserido.

$\mathrm{O}$ direito produzido deve servir à sociedade e, para tanto, não há como negar aos indivíduos que compõem a sociedade, a possibilidade de interpretar e transformar o direito em práticas para além das institucionalizadas.

Assim, a liberação das amarras teóricas e a viabilização do reconhecimento da sensocomunização do conhecimento jurídico, realiza a assimilação de novas práticas às normas postas no texto constitucional, concretizando uma atividade que diz respeito a todos os membros da sociedade, que é de todos (HÄBERLE, 1997, p.24).

Neste passo, não há como negar que o direito na sociedade se projeta para além das fronteiras da normatização e associado aos demais elementos que promovem o desenvolvimento da vida em sociedade, tal qual a tecnologia, torna-se necessariamente um intérprete da norma jurídica, como bem coloca Peter Häberle, ao abordar a questão da interpretação da Constituição para além dos interpretes jurídicos, estendendo tal atividade aos demais indivíduos que vivem a norma:

Todo aquele que vive no contexto regulado por uma norma e que vive com este contexto é, indiretamente ou, até mesmo diretamente um intérprete dessa norma. O destinatário da norma é participante ativo, muito mais ativo do que se pode supor tradicionalmente, do processo hermenêutico. Como não são apenas os intérpretes jurídicos da Constituição que vivem a norma, não detêm eles o monopólio da interpretação da Constituição.

Partindo desse entendimento da necessidade de ver o direito para além do campo circunscrito da atividade de normatização social, partindo para a sua atividade primaz que é a de normalizar as condições de vida dos participantes ativos da sociedade, os quais devem ser vistos na sua perspectiva plural, não há como negar a que a normalização da relação entre o direito e a tecnologia, perpassa a apreensão que os indivíduos tem das possibilidades do uso desta e da sua legitimação pelas normas jurídicas que regem a sociedade.

Diante disso, se impõe aqui a necessidade de entender o lugar da tecnologia como produto da cultura.

A tecnologia pode ser vista a partir de duas perspectivas: inicialmente como estudo da produção tecnológica, possuindo, em razão disso, uma dimensão analítica interdisciplinar; e, também, é percebida como produto, instrumento de apropriação e utilização nas diversas atividades desenvolvidas pelo homem, individualmente e no plano relacional social. 
No plano do campo de produção do conhecimento, a tecnologia consiste no estudo da técnica. Essa, por sua vez, constitui-se em uma das dimensões fundamentais à transformação do homem e da sociedade, pois se estabelece como uma das distinções marcantes da humanidade do homem como agente de transformação cultural, social e econômica (LEVY, 1990, p. 9).

A tecnologia tida como campo de conhecimento não se estabelece num plano disciplinar, pois se manifesta em diversas áreas do conhecimento, projetando-se como essencialmente interdisciplinar. Noutro plano ela se estabelece como produto tecnológico que instrumentaliza e aperfeiçoa a ação humana. Tal situação é verificada em processos de natureza tangível como: a linguagem e demais signos que possibilitam a comunicação; a informática em todas as suas dimensões; meios de produção, de transporte, mobiliário e demais entes passíveis de reificação pelo homem.

No plano relacional com a sociedade, a tecnologia, tida aqui, a priori, na sua dimensão lata, não determina a sociedade, nem é por ela determinada. A tecnologia é a sociedade. A complexidade que envolve o ser tecnológico, o torna a própria sociedade, pois tem em si imanente a cultura de uma dada sociedade. Não há como estabelecer na relação sociedade e tecnologia padrões de determinismo, vez que a sociedade não pode ser compreendida sem seus dispositivos tecnológicos e estes não se constituem como antecedentes constitutivos daquela, pois com ela existe numa relação orgânica de coexistência (CASTELLS, 2005, p. 43).

Tal situação acaba por visibilizar elementos relacionais amplos entre a sociedade e o direito, principalmente na perspectiva ética, impondo a ampliação do círculo dos intérpretes das normas jurídicas, em especial da Constituição, aprofundando, por meio desse processo a integração da realidade que se transforma a todo momento com a inserção das novas tecnologias (HÄBERLE, 1997, p.30), projetando seus reflexos, inclusive, nas práticas de concretização do direito e no modo de sua aplicação.

Tomados os elementos trazidos aqui de forma específica e tópica, e considerando que o que se quer no presente artigo é abertura para a reflexão sobre as relações que possibilitam a associação conceitual existente entre sociedade, direito e tecnologia, partir-se-á para um olhar sobre quais parâmetros metodológicos o estudo desta relação pode ser realizado, a fỉm de que a compreensão fenomênica se dê a partir de uma amplitude complexa, proporcionando, com isso, principalmente, novos prismas sobre o poder de transformação da sociedade diante da interação do direito com a tecnologia.

\section{PRESSUPOSTOS METODOLÓgICOS PARA O ESTUDO DA RELAÇÃO ENTRE SOCIEDADE, DIREITO E TECNOLOGIA}

A produção do conhecimento se dá por meio de estudos pautados em diversos parâmetros técnico-científicos, que, ao se diferenciarem, marcam o saber produzido podendo configurá-lo como ciência, refletindo, por consequência, a qualificação do seu lugar de produção, o qual pode ser proveniente de um paradigma hegemônico ou periférico.

Além disso, o saber produzido reflete o "estado da arte" no espaço e no tempo da produção do conhecimento, integrando, por meio disso, o pesquisador e o objeto de pesquisa ao modo de desenvolvimento do estudo desenvolvido, ampliando ou restringindo a resolução dos problemas em questão.

Com a finalidade de se chegar ao atual referencial metodológico para o estudo da relação existente entre sociedade, direito e tecnologia, cabe uma remissão histórico-teórica do processo de conhecimento e da ampliação das possibilidades que transitam entre a disciplinaridade e transdisciplinaridade.

A racionalidade como padrão de conhecimento hegemônico se estabeleceu na modernidade e ainda hoje situa-se como modelo hegemônico de conhecimento científico. Esse modelo de produção do conhecimento se estabeleceu a partir dos estudos das ciências naturais, 
projetando-se como paradigma aos demais campos do conhecimento como modelo de validação científica (SANTOS, 2006, p. 21).

No transcorrer dos séculos XVI ao XIX, o racionalismo científico legou às modalidades de conhecimento que não se enquadravam no seu espectro metodológico, típico das ciências naturais, o estigma de formas de conhecimento não científico, colocando-os à margem da verdade aceita como científica.

Os conhecimentos classificados como não científicos eram, e em certa medida ainda são, considerados como perigosos, "potencialmente perturbadores" (SANTOS, 2006, p. 21), passíveis do policiamento e controle social do Estado e de instituições sociais como a religião, a família, a escola, a Universidade, entre outras, que ao desqualificá-lo diminuem a sua validade tornando-os menos verdades que as científicas. Dentre os conhecimentos tidos como não científicos, no percurso dos séculos XVI ao XIX, encontram-se o senso comum e as humanidades, inseridas entre elas os estudos históricos, jurídicos, sociológicos, filosóficos, etc. (SANTOS, 2006, p. 21).

De forma estruturada e institucionalizada, o conhecimento qualificado como científico ampliou a sua hegemonia, tendo por contexto a especialização disciplinar desenvolvida nos meios acadêmicos universitários no transcorrer do século XIX e, principalmente, na primeira metade do século XX (GRANGER, 1994, p.11).

A sistematização e desenvolvimento do conhecimento passaram a ser firmados sobre bases rígidas, quantificáveis, passíveis de testes que confirmassem com o máximo possível de exatidão as premissas e hipóteses apresentadas. Todo e qualquer objeto do conhecimento que não se enquadrasse nesse parâmetro de pesquisa, não poderia ser qualificado como científico. A racionalidade, na sua feição objetiva, se sobrepôs às demais expressões do saber, legando às subjetividades um lugar de marginalidade, pois trazia consigo traços de incertezas e relativizações.

As humanidades, em especial o direito, a Sociologia, a História, a Antropologia, a Psicologia, as Ciências Políticas e a Economia, passaram a utilizar parâmetros metodológicos típicos das ciências naturais, para, por meio disso, se aproximar delas e das ciências exatas, e conquistar o status de conhecimento científico. Tal fato as aproximou do modelo hegemônico e as qualificou como ciências. Ocorre que, no momento que tal situação se deu já ocorriam fissuras no modelo científico hegemônico.

Paralelo ao fortalecimento do modelo disciplinar e departamentalizado de ciência, novas forças de produção do conhecimento emergiam e se estabeleciam como verdades possíveis de viabilização de transformação do modelo de produção científica institucionalizado. Os padrões metodológicos não davam mais conta da nova realidade sociocultural, impondo, com isso, novas estruturas de saber e produção.

A teoria da relatividade de Albert Einstein; os estudos de Heisenberg e Bohr acerca da interferência do observador no objeto estudado, quebrando o padrão de neutralidade científica, ao estabelecer o princípio da incerteza; e o teorema da incompletude de Gödel, são algumas das múltiplas fissuras no paradigma científico hegemônico (SANTOS, 2006, p. 45)

Kenneth Arrow e Ilya Prigogine, Michel Serres, Heinz von Foerster, Paul Watzlawick, Terry Winograd, Thomas Kuhn, entre outros cientistas, filósofos, historiadores, juristas, antropólogos, sociólogos, lançaram novas bases ao paradigma científico, abrindo caminho a novas percepções da realidade e do saber científico, o qual passou a se desenvolver por interação de métodos e abordagens, transpondo as barreiras disciplinares em proporções amplas, gerando um conhecimento complexo, multidisciplinar, interdisciplinar e transdisciplinar (GUITTA, 1993, p. 12).

A emergência de um novo modo de construir o conhecimento impôs a quebra dos rígidos padrões disciplinares, binários de ciência e não ciência, tornando possível o diálogo entre os campos do saber, promovendo, com isso, a pesquisa multidisciplinar, interdisciplinar e transdisciplinar. 
A interdisciplinaridade e a transdisciplinaridade ao se estabelecerem como perspectivas metodológicas, a partir do contexto de novos níveis de realidade, colaborou com o surgimento da pluralidade complexa. Essa, por sua vez, provém da hiperespecialização disciplinar, a qual, também, promove a multiplicação de disciplinas, que acabam por convergir a um ponto em comum, gerando o conhecimento complexo (SILVA, 2009, p.23-24).

Assim, há de se reconhecer que a nova configuração da produção científica, diferentemente do modelo hegemônico racionalista de matriz cartesiana, lança novas relações e novos padrões aos fundamentos metodológicos das pesquisas outrora realizadas: o rigor, a abertura e a tolerância (NICOLESCU, 1999, p.129).

$\mathrm{O}$ atual contexto das pesquisas científicas, ao mesmo tempo que ampliam o rigor e o controle metodológico, se abrem a novas possibilidades de interação, tolerando e conciliando os padrões da racionalidade com os das subjetividades. Com isso, abre-se a possibilidade das interações entre conhecimentos produzidos em áreas distintas como o da Sociologia, o do Direito e os das Tecnociências (SILVA, 2010, p. 32-33).

A sociedade, o direito e a tecnologia como objetos de estudo da Sociologia, do Direito e das Tecnociências, a partir da interdisciplinaridade, se submetem a construções teóricas pautadas no rigor científico, fundado nas modalidades de raciocínio como o lógico-dedutivo, o indutivo, o dialético, mas se abrem, também, à Hermenêutica ${ }^{1}$ e suas correntes específicas como a fenomenológica em suas diversas possibilidades: existencial, histórica, filosófica.

A abertura ao diálogo metodológico e a tolerância com as diferenças teóricas fundantes ampliam a percepção sobre o objeto estudado. $\mathrm{O}$ direito ao analisar as possibilidades de aplicação das novas tecnologias às suas práticas, a exemplo do desenvolvimento do processo judicial eletrônico, a partir de estudos sociológicos jurídicos relacionados à administração da justiça, ao acesso à justiça e à efetividade dos direitos humanos, rompe com paradigmas científicos aplicados aos estudos dos seus clássicos objetos.

Nesse plano, o direito acaba por se deixar influenciar metodologicamente e se submeter à realidade coexistente, no plano da pesquisa científica, desenvolvida pelas Tecnociências e pela Sociologia, para no plano prático ampliar o seu campo de ação e efetividade.

A materialização da complexidade do conhecimento nos estudos interdisciplinares que envolvem a sociedade, o direito e a tecnologia, se impõe como essencial à nova realidade sociocultural, principalmente no que tange à realização dos direitos no espaço-tempo globalizado.

Aqui se visibiliza algumas questões que elevam a importância de situar os elementos teóricos e metodológicos da relação existente entre sociedade, direito e tecnologia, mostrando-se como a que se impõe em primazia, as questões da responsabilidade e da ética.

Tal situação se visibiliza na insistente dicotomia que perpassa, historicamente, a relação existente entre o homem e a máquina, entre o direito e a tecnologia e suas continuidades e descontinuidades, geradoras de "certezas e incertezas".

$\mathrm{Na}$ busca de respostas à superação que decorre do sistema dicotômico que insiste em se manter nos paradigmas metodológicos hegemônicos, Maria Lucia Levy Malta (2002), ao analisar o Direito da Tecnologia da Informação, mais especificamente as questões ligadas ao e-commerce, remete tais relações a uma necessária reflexão sobre a responsabilidade e a ética na interação ora estuda.

Não por outra razão, se coloca em destaque que a superação das dicotomias limitativas a um maior entendimento da importância relacional do direito com a tecnologia para o conjunto

\footnotetext{
${ }^{1}$ Aqui fica patente a importância de teóricos como Peter Häberle (1997), que fixam como necessária a abertura teórica e interpretativa das normas jurídicas, em especial da Constituição, como meio de compreensão da realidade vivida num plano relacional e vivenciada intimamente. Situação que impõe a todo que "vive a norma, interpretá-la ou cointerpretá-la" (HÄBERLE, 1997, p.13). Transformando e sendo transformado pelo direito e sua interação com outros fenômenos sociais com o tecnológico, que, também, promove modificações no plano da existência e nas relações sociais.
} 
social, situa-se justamente em cuidados de natureza metodológica e que a interdisciplinaridade/transdisciplinaridade deve ser praticada para um melhor assimilação da interface que se estabelece entre o homem e a tecnologia, entre o direito e a tecnologia, pois a transposição entre o real e o virtual se processa em um plano diferenciado do usualmente mensurado levando a novas percepções da realidade e das relações a ela inerentes, como a do direito com a tecnologia (MALTA, 2002, p. 29).

Por tais razões, a emergência de novas soluções requisita novas formas de percepção do conhecimento. E a interdisciplinaridade/transdisciplinaridade se impõe como agente metodológico para o estudo da relação entre sociedade, direito e tecnologia, na busca de novas soluções aos velhos problemas que envolvem a concretização dos direitos, principalmente daqueles qualificados como fundamentais para revelar a importância do direito no constructo denominado Sociedade da Informação.

\section{O DIREITO E SUA INSERÇÃO NA SOCIEDADE DA INFORMAÇÃO}

O direito se constitui como fenômeno social decorrente de fato cultural e como tal, em seus aspectos dogmáticos, normativos e institucionais não pode prescindir de uma interrelação com o contexto histórico, social, cultural e econômico que o circunda.

A sua compreensão como um fato social e inserção na Sociedade da Informação pressupõe a compreensão desse cenário, seu modo de desenvolvimento e suas instituições fundamentais à formação de sistemas interacionais como o político, o econômico, o de comunicação e o de poder nas suas diversas dimensões.

Desde os anos de 1970, Alvin Tofler (2007) destacou a emergência de uma Sociedade da Informação. Era a terceira onda: a era da informação; do surgimento e desenvolvimento da tecnologia digital que culminou na criação da internet; da difusão dos equipamentos informáticos da microeletrônica e do aumento vertiginoso de sua capacidade de processar informações; do desenvolvimento da engenharia genética; da velocidade cada vez maior da transmissão das informações e a origem descentralizada delas.

A descoberta das novas tecnologias e o processo de transformação tecnológica na década de 1970 concentrou-se, sobretudo nos Estados Unidos, em virtude de seu contexto social, marcado pela grande crise econômica que motivou uma reestruturação profunda no sistema capitalista em escala global. O novo sistema tecnológico deve ser atribuído à dinâmica da descoberta e difusão tecnológica em um contexto influenciado por fatores institucionais, econômicos e culturais: o microprocessador possibilitou o microcomputador; os avanços em telecomunicações possibilitaram que os microcomputadores funcionassem em rede; novos softwares foram surgindo em virtude da difusão dos microcomputadores e outras descobertas foram se seguindo (CASTELLS, 2005, p. 97-98).

Tal cenário de inovações técnicas, organizacionais e administrativas interrelacionadas constrói o paradigma da tecnologia da informação, e na medida em que modifica a dinâmica da estrutura dos custos relativos de todos os possíveis insumos para a produção, promovendo a interação entre economia e sociedade, trilha o caminho para uma transformação estrutural e representa a base material da Sociedade da Informação. Algumas características marcam esse paradigma, Manuel Castells (2005) se propõe a analisá-las.

A primeira característica é que a informação se constitui como matéria prima fundamental, assim as tecnologias são criadas para agir sobre as informações e não apenas as informações agem sobre a tecnologia (CASTELLS, 2005, p. 108). A informação tem o caráter de riqueza inesgotável, de forma que os bens podem ser infinitamente duplicados, a exemplo das mídias digitais e dos softwares. 
A segunda característica diz respeito a penetrabilidade dos efeitos das novas tecnologias em toda atividade humana, com isso, todos os processos da existência humana individual e coletiva são moldados pelo meio tecnológico (CASTELLS, 2005, p. 108).

A terceira característica consiste na utilização da morfologia da rede e qualquer sistema ou conjunto de relações, utilizando as tecnologias da informação. A lógica das redes vai se adaptando à complexidade das interações, se integrando a processos e organizações, modificando as relações entre os indivíduos na sociedade (CASTELLS, 2005, p. 108).

A quarta característica é a flexibilidade e capacidade de reconfiguração. Os processos, as organizações e as instituições são reversíveis, podem ser modificadas e alteradas pela reorganização de seus componentes. Isso reflete uma sociedade marcada por constantes mudanças e fluidez organizacional, sendo possível mudar regras sem destruir a organização porque a base material da organização pode ser reprogramada e reaparelhada (CASTELLS, 2005, p. 109).

A quinta característica é a crescente convergência de tecnologias específicas para um sistema altamente integrado. Dessa forma, a microeletrônica, as telecomunicações, a optoeletrônica e os computadores são todos integrados no sistema de informação. Essa convergência tecnológica provoca uma interdependência entre as revoluções em biologia, microeletrônica e nanotecnologia, tanto em relação a materiais como em relação a métodos (CASTELLS, 2005, p. 109-110).

Essa nova estrutura social verifica-se manifestada das mais diversas maneiras de acordo com a variedade de culturas e instituições e encontra-se associada a um modo inovador de desenvolvimento econômico, o informacionalismo, moldado pela reestruturação do modo de produção capitalista, o qual se destaca pela convergência tecnológica e digital, pelo crescimento exponencial da produção de equipamentos informáticos e pela disseminação mundial da internet (CASTELLS, 2005, p. 51).

Como principal marca econômica dessa sociedade, o informacionalismo reorganiza a produção de riqueza, gerando uma gradativa valoração da informação como mercadoria e fator de geração de valor econômico (BARRETO JUNIOR, 2015, p. 410). A fonte de produtividade reside na tecnologia de geração de conhecimentos, de processamento da informação e de comunicação de símbolos (CASTELLS, 2005, p. 53). Manuel Castells detalha sobre esse modo de desenvolvimento:

[...] o que é específico ao modo informacional de desenvolvimento é a ação de conhecimentos sobre os próprios conhecimentos como principal fonte de produtividade. O processamento da informação é focalizado na melhoria da tecnologia do processamento da informação como fonte de produtividade, em um círculo virtuoso de interação entre as fontes de conhecimento tecnológicos e a aplicação da tecnologia para melhorar a geração de conhecimentos e o processamento da informação: é por isso que, voltando à moda popular, chamo esse novo modo de desenvolvimento de informacional, constituído pelo surgimento de um novo paradigma tecnológico baseado na tecnologia da informação (CASTELLS, 2005, p. 54).

Um novo padrão de sociabilidade humana, resultante das transformações dos paradigmas sociais, econômicos, tecnológicos, culturais e jurídicos se inicia com o advento da Sociedade da Informação. $\mathrm{O}$ relacionamento humano alcança um novo patamar, mediado pela tecnologia. $\mathrm{O}$ homem informacional, como produto direto da revolução tecnológica, conecta-se em tempo real, por meio de redes de computadores que crescem de maneira exponencial, disseminando formas e canais de comunicação que moldam as relações sociais e são moldados por estas (BARRETO JUNIOR, 2015, p. 408). A nova sociabilidade se interconecta pelo conteúdo das comunicações, que se materializou através da informatização e se expandiu pela disseminação da internet em escala mundial. 
A revolução da tecnologia da informação, como as demais revoluções tecnológicas, é caracterizada pela permeabilidade em todos os domínios da atividade humana, não exatamente como uma fonte de impacto externo, mas como um tecido em que a atividade humana é exercida (CASTELLS, 2005, p. 68).

O maior ou menor grau de transformação tecnológica no seio social depende de um complexo padrão interativo, de forma que a sociedade, por meio do Estado, poderá determinar a velocidade e a extensão dessas mudanças.

Nesse sentido, esse novo paradigma social proporcionado pelas transformações tecnológicas, com as dificuldades em definir limites territoriais e físicos, complexado pela velocidade com que as decisões devem ser tomadas, impõe um grande desafio para o direito: o de se adequar a essa nova sociedade.

Um bom exemplo das transformações decorrentes da intervenção da tecnologia com impacto no direito situa-se nas mídias de comunicação, estas "não transmitem o que ocorre na realidade social, elas impõem o que constroem no espaço público" (CHARAUDEAU, 2013, p. 19), levando o direito a limites interpretativos, nunca antes vistos.

A estrutura social inaugurada pela Sociedade da Informação impõe ao direito uma transformação para oferecer respostas aos conflitos surgidos. A globalização da sociedade exige a globalização do pensamento jurídico, de forma a criar mecanismos jurídicos que extrapolem os princípios da territorialidade e se adequem aos produtos, relações e interações geradas no seio da Sociedade da Informação.

O direito precisa estar apto a responder a todas as mudanças geradas pela revolução da tecnologia da informação. Desde as novas formas de produção de insumos e de produtos gerados pela tecnologia, passando pelos novos modelos de relações produtivas e laborais, a instantaneidade dos processos de comunicação e o aumento da capacidade de acesso à informação tornaram-se os novos imperativos categóricos a serem assimilados e praticados pelo direito.

Desde a sua origem normativa, voltada ao fato in abstrato, até a sua concretização individualizada por meio do processo, através da decisão judicial, o direito deve se inserir nas novas possibilidades de existência e de vivências configuradas na Sociedade da Informação.

A imersão do direito na nova realidade dar-se-á tanto no seu lugar de produção do conhecimento, quanto na de norma posta, voltada a aplicabilidade no processo de prestação jurisdicional. A transformação a ser empreendida no âmbito jurídico deve observar a abertura e a tolerabilidade às novas possibilidades de lugares de poder virtualizados, tais quais o ciberespaço, para a partir da renovação de seus institutos e da criação de outros, tutelar os bens jurídicos reconfigurados nessa realidade transformada pela tecnologia.

O Estado, no exercício de sua função legislativa, passa a ter a missão de compreender as transformações e os novos padrões sociais que vão se estabelecendo para elaborar normas que sejam mais aderentes a realidade atual e possam ser implementadas com eficácia e efetividade.

No âmbito do Judiciário, o Magistrado tem tido a tarefa de enfrentar debates e conflitos em torno de temas ainda não normatizados, o que abre espaço para reflexões sobre as transformações que o direito tem passado, em razão da atuação das múltiplas possibilidades de uso da tecnologia, bem como da ação dos seus produtos nas relações interindividuais, distintas, mas, em alguns aspectos, semelhantes ao da realidade analógica em processo de superação.

No âmbito da participação na vida do Estado, a própria noção de cidadania e de cidadão ganha um novo significado, a cidadania transcende à materialidade física e ganha o slogan de cidadania digital. O cidadão como o indivíduo integrado na vida estatal, partícipe da vida política, passa a ter acesso aos direitos sociais e às informações sobre a atuação estatal, a partir de sua inserção no ciberespaço, por meio de ferramentas disponíveis na rede mundial de computadores.

As fronteiras físicas do conhecimento têm se esmaecido, continuam a existir, mas encontram-se passíveis à invasão do poder exercido pela tecnologia da informação. O lugar do 
direito na Sociedade da Informação continua sendo um lugar de poder abrangente e tende, com a sua adaptabilidade e complexidade, a ampliar o seu espaço de atuação.

Por isso, não há como negar que o direito ao se abrir ao novo, assumindo que a sua ação e efetividade depende da tecnologia, que, na nova realidade sociocultural virtualizada, tornou-se um instrumento de transformação e ação dos mecanismos de controle das relações sociais, do qual não se deve prescindir mais fundir-se, realizá-lo por meio dos seus dispositivos, num processo de mútua transformação e existência, voltadas à efetivação dos direitos fundamentais, principalmente, o acesso à justiça substancial.

\section{CONSIDERAÇÕES FINAIS}

Diante da perspectiva reflexiva do presente artigo, fica patente que a compreensão da complexa relação existente entre sociedade, direito e tecnologia, bem como a inserção do direito na Sociedade da Informação, se dá a partir de meandros profundos, que devem ser percebidos, estudados, experimentados e adaptados às suas funcionalidades, principalmente, no que toca ao direito e a sua função de controle social.

Os elementos fundantes da sociedade, do direito e da tecnologia situam-se na cultura humana. Logo, ao se originar do saber e do agir humano, tais fenômenos operam em múltiplos processos cíclicos de operação/transformação/funcionalização, os quais se voltam ao homem, para além da sua individualidade, regulando e movendo a sua existência, levando-o a novos patamares relacionais e a novas percepções de realidade.

As reflexões sobre a relação entre sociedade, direito e tecnologia devem partir de novas concepções teórico-metodológicas. A marca dessas novas possibilidades de análise e pesquisa está nos estudos interdisciplinares, os quais tem se tornado um novo caminho, a ser trilhado, fomentado e praticado no desenvolvimento do saber jurídico e das possibilidades de sua operabilidade no plano empírico.

Um exemplo do impacto da relação existente entre o direito e a tecnologia e a sua repercussão social, está na transformações que tem ocorrido na forma de prestação jurisdicional através do processo judicial eletrônico, ampliando as formas de acesso à justiça aos jurisdicionados.

Por meio dos mecanismos da informática os processos podem ser acessados fora dos Tribunais por meio de plataformas na internet, permitindo não só a ampliação da publicidade, com também do acesso.

Tais facilidade, no entanto, não vem sem questionamento e pontos controvertidos a serem resolvidos, não só pelos operadores do direito, mas, sobretudo, pelo conjunto social, num processo amplo de conhecimento dos processos e mecanismos de implementação desses instrumentos de prestação jurisdicional.

Desse modo, não há como negar que a Sociedade da Informação ainda traz consigo aspectos que demandam maior aprofundamento e estudo, principalmente quanto a situações que geram incertezas de natureza dicotômicas que envolvem a velha parêmia homem versus máquina.

Mas não há como negar, também, que a associação entre o direito e a tecnologia amplia as múltiplas possibilidades existenciais no plano individual e tem transformado as relações sociais, e que a tecnologia se constitui num espaço de saber e instrumento de poder sem igual, não podendo o direito perder de vista o seu lugar no processo de desenvolvimento tecnológico continuamente em curso.

Por fỉm, não há como negar a importância da reflexão sobre a atuação do direito na normatização e normalização da Sociedade da Informação e a necessidade dele deixar-se transformar, para, com isso, conformar-se às novas possibilidades existenciais de exercício do poder que lhe é peculiar, realizando, com isso, de forma ampla os direitos fundamentais, em especial o acesso à justiça e a prestação jurisdicional. 


\section{REFERÊNCIAS}

BARRETO JUNIOR, Irineu Francisco. Proteção da Privacidade e de dados pessoais da internet: o marco civil da rede examinado com fundamento nas teorias de Zygmunt Bauman e Manuel Castells. In: LUCCA, Newton de; SIMÃO FILHO, Adalberto. Direito e Internet III: marco civil da internet lei n. 12.965/2014. Tomo I. São Paulo: Quartier Latin, 2015.

BOTTOMORE, T. B. Introdução à Sociologia. 9. ed. Rio de Janeiro: LTC, 1987.

CASTELLS, Manuel. A Sociedade em Rede. A Era da Informação: economia, sociedade e cultura. v. 1. São Paulo: Paz e Terra, 2005.

CHARAUDEAU, Patrick. Discursos das mídias. 2. ed. São Paulo: Contexto, 2013.

GIDDENS, Anthony. Sociologia. 6. ed. Lisboa: Fundação Calouste Gulbenkian, 2008.

GRANGER, Gilles Gaston. A Ciência e as Ciências. São Paulo: Editora UNESP, 1994.

GUITTA, Pessis-Pasternak. Do caos à inteligência artificial: quando os cientistas se interrogam. São Paulo: Editora UNESP, 1993.

HÄBERLE, Peter. Hermenêutica Constitucional. A sociedade aberta dos intérpretes da Constituição: contribuição para a interpretação pluralista e "procedimental" da Constituição. Porto Alegre: Sergio Antonio Fabris Editor, 1997.

LEVY, Pierre. As Tecnologias da Inteligência: o futuro do pensamento na Era Informática. Lisboa: Edições Piaget, 1990.

MALTA, Maria Lucia Levy. Direito da Tecnologia da Informação. Campinas: Edicamp, 2002.

NICOLESCU, Basarab. O Manifesto da Transdisciplinaridade. São Paulo: TRION, 1999.

PASSOS, J. J. Calmon de. Direito, poder, justiça e processo. Rio de Janeiro: Editora Forense, 2000.

REALE, Miguel. Fundamentos do Direito. 3. ed. São Paulo: Revista dos Tribunais, 1998.

SANTOS, Boaventura de Sousa. Um discurso sobre as ciências. 4. ed. São Paulo: Cortez, 2006.

SILVA, Adilson Cunha. As tecnociências e o redimensionamento da responsabilidade civil. Dissertação (Mestrado em Direito) - Faculdade de Direito, Universidade Federal da Bahia. Salvador: 2009.

Direito, Bioética e tecnociências/biotecnociências: a emergência de um novo paradigma científico para as pesquisas jurídicas sobre novas tecnologias. In: PAMPLONA FILHO, Rodolfo; CERQUEIRA, Nelson; SANTANA JÚNIOR, Gilson Alves de. Metodologia da pesquisa em Direito. v.1. Salvador: Couto Coelho, 2010.

TOFFLER, Alvin. A terceira onda. Rio de Janeiro: Record, 2007. 